Rev. Interd. em Cult. e Soc. (RICS), São Luís, v. 7, n. 2, p. 31- 41, jul./dez. 2021

ISSN eletrônico: $2447-6498$

\title{
O Rubor de Corday e os Estudos da Irritabilidade e da Sensibilidade nos Séculos XVIII e XIX ${ }^{1}$
}

\section{Corday's Flushing And The Studies Of Irritability And Sensitivity In The 18th And 19th Century}

\author{
ANA CAROLINA SOLIVA SORIA ${ }^{2}$ \\ Docente do Departamento de Filosofia da UFSCar e \\ bolsista de Produtividade em Pesquisa do CNPq. \\ anasoliva@ufscar.br
}

\section{RESUMO}

Este artigo realiza uma breve retomada das ideias de alguns autores que discutiram se a sensibilidade e o pensamento persistiam nas cabeças decepadas dos condenados à guilhotina. Na controvérsia entre opiniões, os autores discutem a possibilidade de as partes do corpo, separadas do centro comum de sensibilidade, terem dor, ou se cabeça cortada permaneceria viva por alguns momentos após a decapitação, e se sofreria ou pensaria. Nessa retomada, discutiremos algumas questões relacionadas à irritabilidade, sensibilidade e unidade da consciência.

Palavras-chave: Charlotte Corday. Guilhotina. Irritabilidade. Sensibilidade. Consciência.

\begin{abstract}
This paper conducts a brief review of the ideas of some authors who discussed if sensibility and thought persisted in the severed heads of those condemned to the guillotine. In the controversy between opinions, the authors discuss the possibility that body parts, separated from the common center of sensibility, could have pain, or whether severed heads would remain alive for a few seconds after decapitation, and whether they would suffer or think. In this review, we will discuss some issues related to irritability, sensibility and the unity of consciousness.
\end{abstract}

Keywords: Charlotte Corday. Guillotine. Irritability. Sensibility. Consciousness.

\footnotetext{
${ }^{1}$ Artigo submetido para avaliação em 21 de setembro de 2021 e aprovado em 20 de outubro em 2021.

${ }^{2}$ Uma versão preliminar deste texto foi apresentada como conferência no X Encontro de Pesquisa na Graduação em Filosofia da UFSCar.
} 
Rev. Interd. em Cult. e Soc. (RICS), São Luís, v. 7, n. 2, p. 31- 41, jul./dez. 2021

ISSN eletrônico: 2447-6498

\section{INTRODUÇÃO}

No início de Vigiar e punir, Foucault nos apresenta um projeto de reformulação do código penal francês apresentado pelo Dr. Guillotin à Assembleia Constituinte em $1^{\circ}$ de dezembro de 1789 . O texto por ele submetido dizia o seguinte: "Os delitos de mesmo gênero serão punidos pelo mesmo gênero de pena, quaisquer que sejam a posição social ou condição do culpado [...]" (FOUCAULT, 1975, p. 18). Até então, o tipo de pena aplicado aos condenados se diferenciava segundo a classe a que eles pertenciam. A pena capital para a nobreza, por exemplo, era a decapitação (não pela guilhotina, que passou a ser utilizada a partir de 1792), ao passo que outros condenados poderiam ser postos sobre a roda, depois açoitados, esticados por cordas atreladas a cavalos, e finalmente esquartejados ou deixados para morrer de fome, ou ainda submetidos a outros procedimentos que a imaginação ilimitada do gênero humano não se poupou de figurar. Guillotin, que não é o inventor da guilhotina, mas preconizou que o criminoso deve ser decapitado "pelo efeito de um simples mecanismo" (BUCHEZ apud CHAMAYOU, 2008, p. 335), entrou para a história por conta dos elogios rendidos a ele pelo jornal Le Moniteur de 18 de dezembro de 1789, que o qualificou como "[...] o primeiro que, em uma assembleia de legisladores, falou de suplícios com humanidade [...]" (CHAMAYOU, 2008, p. 335). A democratização das penas somada aos esforços de erradicar o martírio corporal em suas execuções permitiu a redação do "[...] famoso artigo 3 do código francês de 1791 - 'todo condenado à morte terá a cabeça decepada'." (FOUCAULT, 1975, p. 18). Estamos, ainda segundo Foucault, em um momento em que o espetáculo punitivo, o cerimonial da pena, a confissão pública dos crimes, os açoitamentos públicos, a exposição dos condenados em grilhões, submetidos a injúrias, zombarias, pancadarias vão se extinguindo. Nas palavras do autor:

A punição tende, pois, a se tornar a parte mais oculta do processo penal. $\mathrm{O}$ que ocasiona várias consequências: deixa o domínio da percepção quase cotidiana para entrar no da consciência abstrata; [...] a mecânica exemplar da punição muda suas engrenagens. [...] De um modo geral, as práticas punitivas tornaram-se pudicas. Não tocar mais no corpo, ou, em todo caso, o mínimo possível, e para atingir nele algo que não é o próprio corpo. Dir-se-á: a prisão, a reclusão, os trabalhos forçados, a prisão para forçados, a interdição de domicílio, a deportação - que ocuparam um lugar tão importante nos sistemas penais modernos - são somente penas "físicas": ao contrário da multa, recaem diretamente sobre o corpo. Mas a relação punição-corpo não é 
Rev. Interd. em Cult. e Soc. (RICS), São Luís, v. 7, n. 2, p. 31- 41, jul./dez. 2021 ISSN eletrônico: $2447-6498$

idêntica ao que era nos suplícios ${ }^{3}$. O corpo encontra-se aí em posição de instrumento ou de intermediário; se se intervém sobre ele encarcerando-o, ou fazendo-o trabalhar, é para privar o indivíduo de uma liberdade considerada ao mesmo tempo como um direito e um bem. Segundo essa penalidade, o corpo é posto em um sistema de coação e de privação, de obrigações e de interdições. O sofrimento físico, a dor do próprio corpo não são mais os elementos constitutivos da pena. A punição passou de uma arte das sensações insuportáveis a uma economia dos direitos suspensos. Se é preciso ainda que a justiça manipule e atinja os corpos dos sujeitos à jurisdição, isso será à distância, segundo regras austeras, e visando um objetivo muito mais “elevado". Por efeito dessa nova detenção, toda uma tropa de técnicos veio substituir o carrasco, anatomista imediato do sofrimento: os vigias, médicos, capelães, psiquiatras, psicólogos, educadores. [...] A guilhotina utilizada a partir de março de 1792 é a mecânica adequada a esses princípios. A morte é então reduzida a um evento visível, mas instantâneo. Entre a lei, ou aqueles que a executam, e o corpo do criminoso, o contato é reduzido ao intervalo de um raio. (FOUCAULT, 1975, p. 15).

Ora, sob essa perspectiva, isto é, sob a mudança de objeto sobre o qual deve recair a pena, não mais sobre o corpo, mas sobre algo incorpóreo, abstrato, a saber: o direito à liberdade ou à vida - é sob essa perspectiva que o maquinário preciso será inventado. Não será como aqueles já existentes, de lâmina horizontal, que precisava descer umas duas ou três vezes, e que ficavam longe de alcançar a precisão metódica desejada. $\mathrm{O}$ artigo $3^{\circ}$ do código penal de 1791 somado à necessidade de quase não tocar o corpo do condenado, permitirá aperfeiçoar a tranche-tête já existente a fim de cumprir a pena de modo "não cruel", "filantropicamente", por assim dizer - para usarmos o termo de Chamayou (2008, p. 334) - capaz de "humanizar" a morte do condenado ao mesmo tempo em que "mecaniza" a aplicação da pena. Para esse fim, o dr. Antoine Louis, secretário vitalício da Academia de cirurgia e ilustre cirurgião legista, é solicitado pela Assembleia em 1792 a se manifestar sobre a máquina de decapitação. Ele não apenas se pronuncia como especialista em cirurgia legal, mas também como médico penal, encarregado de avaliar a administração indolor da pena. Seu informe é publicado no Le Moniteur de 22 de março de 1792:

Os instrumentos cortantes têm apenas pouco ou nenhum efeito quando cortam perpendicularmente. Ao examiná-los no microscópio, vê-se que são apenas serras mais ou menos finas que se deve fazer agir deslizando sobre os corpos a serem divididos. Não se teria êxito em decapitar de um só golpe com um machado ou cutelo cujo fio fosse em linha reta, mas com uma navalha obliqua. (LOUIS apud CHAMAYOU, 2008, p. 336).

\footnotetext{
${ }^{3}$ Sobre isso, remetemos à exposição feita por Foucault nos primeiros parágrafos do primeiro capítulo de Vigiar e punir, que versa sobre o esquartejamento de Damiens.
} 
Rev. Interd. em Cult. e Soc. (RICS), São Luís, v. 7, n. 2, p. 31- 41, jul./dez. 2021 ISSN eletrônico: $2447-6498$

E a sugestão do dr. Louis é que a nova máquina fosse testada em carneiros e cadáveres. Com esta exemplar colaboração da ciência para o avanço de técnicas mais suaves de morte e à serviço do poder judiciário, foi então conferido a um fabricante de cravos chamado Schmidt, auxiliado por um conhecido carrasco, o sr. Charles-Henri Sanson, a construção do maquinário preciso. Uma vez pronta, a guilhotina foi oficialmente adotada e garantia aos que julgavam, aos executores da pena e também às famílias dos criminosos que a execução aconteceria de maneira indolor e instantânea (isto é, que entre a execução da pena e o seu efeito - a morte - haveria um lapso de tempo imperceptível).

Pois bem, e eis que essa certeza foi posta em dúvida em 17 de julho de 1793, dia em que Charlotte Corday foi guilhotinada. Corday foi condenada pelo assassinado de Marat, criador do jornal L'Ami du peuple, deputado na Convenção durante a Revolução francesa e personagem muito querida do povo.

O fato que põe em dúvida a humanidade da morte por decapitação é narrado por um expectador anônimo da execução da condenada, conta que o seguinte: “[...] quando a cabeça de Charlotte Corday caiu sob a lâmina fatal, o executor, ao mostrá-la ao povo, ousou lhe aplicar dois sopapos. As bochechas se cobriram de um rubor que inquietou todos os olhares [...]" (CHAMAYOU, 2008, p. 337). Segundo registros, o executor era Legros, ajudante do carrasco e carpinteiro, que havia trabalhado no reparo da guilhotina durante todo o dia. Outro espectador relata o seguinte:

[...] apesar de estar familiarizado com esse tipo de espetáculo, tive, contudo, medo. Parecia-me que era em mim que aquele olhar entreaberto estava fixado e que ali reencontrava ainda aquela doçura penetrante e irresistível que havia me aturdido. Por isso, virei a cabeça. Foi apenas por murmúrios que ouvi ao meu redor que o celerado havia esbofeteado a cabeça. Foram os outros que me asseguraram que ela ruboresceu com esse insulto. (SANSON, 1863, p. $148-49)$.

Legros foi condenado à prisão por submeter a uma humilhação infame a cabeça de Charlotte Corday, que ultrapassou em muito o simples ato de execução pretendido pelos legisladores. Além disso, com esse evento, uma terrível dúvida se instalou sobre a qualidade da pena: uma cabeça já sem o corpo poderia efetivamente ruborescer de indignação? Se sim, é porque ela viu o que se passou e continua consciente, mesmo que por pouco tempo, após arrancada do pescoço. A decapitação imporia sofrimentos inimagináveis ao corpo e ao pensamento? O pior dos cenários é 
Rev. Interd. em Cult. e Soc. (RICS), São Luís, v. 7, n. 2, p. 31- 41, jul./dez. 2021 ISSN eletrônico: $2447-6498$

então considerado por aqueles que defendiam a desmaterialização da pena: a cabeça que se vê separada do corpo acompanharia com consciência e dor sua própria morte. A partir desse fato relacionado à decapitação de Corday um importante debate sobre o sentimento, a irritabilidade e a sede da alma terão início, e estabelecerá as bases do que entendemos hoje por consciência e pelo funcionamento do sistema nervoso ${ }^{4}$.

Em 1795, o jornal Le Moniteur publica uma carta do reputado autor de Sobre o órgão da alma, Samuel Thomas Sömmerring, professor de anatomia e cirurgia. A ele devemos o nome dos nervos cranianos. Um posfácio, aliás, - não muito favorável - de Kant foi inclusive publicada no tratado de Sömmerring, o que o tornou conhecido na história da filosofia (KANT, 2007, p. 96). Em sua carta publicada pelo periódico francês, o anatomista alemão defende que a guilhotina é um "tipo de morte horrível", dado que "o sentimento, a personalidade, o eu" continuam vivos na cabeça separada do corpo alguns instantes após a execução. Para ele, "o sentimento [entendido como a faculdade de sentir] não é inteiramente destruído pela decapitação na medida em que 'a sede do sentimento e de sua apercepção está no cérebro' e que 'as operações dessa consciência dos sentimentos podem ser feitas, embora a circulação do sangue pelo cérebro esteja suspensa'." (OELSNER apud CHAMAYOU, 2008, p. 338). Segundo a opinião de Sömmerring, o suplício físico se desmembraria em uma tortura mental: uma vez que a faculdade de sentir não é destruída inteiramente pela decapitação, o cérebro, como sede do sentimento e da apercepção, teria consciência da dor pela ruptura dos feixes nervosos que passam pelo pescoço (na medula espinhal) e pelo golpe violento, bem como consciência de se ver morto. Para reforçar sua opinião, o anatomista recolhe relatos favoráveis à sua tese: Melchior Weikard, médico-filósofo, teria visto os lábios de um homem decapitado se mexerem; Albrecht von Haller teria visto a cabeça de outro homem decapitado ameaçar com o olhar alguém quem ousou tocar sua medula espinhal.

\footnotetext{
${ }^{4}$ Segundo Le Lexis (2009), irritabilidade refere-se "à propriedade geral das células vivas, que respondem a uma estimulação qualquer (mecânica, química, térmica, elétrica ou outra) por uma resposta que caracteriza a natureza de cada tipo de célula: deformação, secreção, etc." e sentimento, à sensibilidade física. Na Enciclopédia, de Diderot e D’Alembert (2015, pp. 304-305), encontramos a seguinte definição para sentimento e sensibilidade: "Sensibilidade é a faculdade de sentir, o princípio sensitivo ou o sentimento mesmo das partes, da base e do agente conservador da vida, a animalidade por excelência [...]. A sensibilidade é, no corpo vivo, uma propriedade que certas partes têm de perceber impressões dos objetos externos e, em consequência disso, produzir movimentos proporcionais ao grau de intensidade da percepção. A primeira dessas ações é a que se chama de sentimento, sensatio, sensus, com respeito à qual a sensibilidade é a faculdade, uma potência reduzida a ato, potentia in acto reduta, como dizem as Escolas. [...] A segunda ação, a mobilidade, é a mera expressão muda desse mesmo sentimento, vale dizer, a impulsão que nos atrai para os objetos ou que nos afasta deles.”
} 
Rev. Interd. em Cult. e Soc. (RICS), São Luís, v. 7, n. 2, p. 31- 41, jul./dez. 2021 ISSN eletrônico: $2447-6498$

O médico Heinrich von Leveling, sob os conselhos de Sömmerring, conduziu experimentos inclusive para determinar o lugar do suplício: ao se irritar a parte da medula espinhal que permanecia ligada à cabeça, assegurou que a face era tomada por terríveis caretas. Diante deste cenário, o enforcamento parece ser a opção mais indolor!

Do lado francês, as teses de Sömmerring recebem apoio de Jean-Joseph Sue, cirurgião militar e professor de anatomia nas Belas Artes e cirurgião na Charité. Autor de Opinião sobre o suplício da guilhotina e sobre a dor que sobrevive à decapitação, defende a existência de dois tipos de sensibilidade: uma que corresponde a uma sensação no lugar mesmo em que se sofre e outra correspondente a consciência ou perceptibilidade desta sensação. Dito de outro modo, tomemos alguém que sofre um mal no dedão do pé. Onde a dor está localizada? Ela não está na cabeça, mas pode-se dizer que a cabeça percebe esta dor por uma correlação com o membro afetado. A cabeça é um centro que percebe a dor, mas que não a sofre enquanto tal, apesar de saber que o pé sofre. Por outro lado, além da dor sentida, há, para Sue, uma dor objetiva, independente da sua consciência. Essa dor é constatada sem a necessidade de lágrimas ou gritos, pois a parte afetada sofre uma modificação de sua cor ou forma. Essa ideia de um duplo suplício é transferida para a guilhotina. Esta duplicaria o sofrimento físico: imporia dor à cabeça cortada (dor sensível, consciente) e aos membros separados da cabeça (dor não consciente). O corpo "sofre como corpo e a cabeça como cabeça" e “[...] não é indiferente, segundo minha opinião, se, quando uma perna é amputada e cauterizada, se há dor; se, quando se irrita um membro qualquer, uma pata de rã, mesmo separada do corpo, se há dor nesta pata." (SUE apud CHAMAYOU, 2008, p. 341).

E como a imaginação humana não tem limites, sobretudo quando se trata de um progresso científico tão significativo, Sue (apud CHAMAYOU, 2008) imagina uma solução experimental para um problema que somente podia ser pensado por observações indiretas, por uma certeza de analogia, de raciocínio, e não pela experiência imediata:

Se fosse combinado com alguns desses infelizes, antes do degolamento, movimentos que dirigissem sua consciência após a execução, por suas pálpebras, olhos ou mandíbulas, para indicar por movimentos acordados se eles teriam consciência de seu suplício... não duvidamos que por amor à humanidade teriam consentido em fazer esta triste experiência para proveito de seus semelhantes. Bailli, Malesherbes, Roland teriam sido capazes de um tal heroísmo; o desafortunado Lavoisier [...] teria agarrado com entusiasmo esta ideia; na impossibilidade de escapar de seus carrascos, teria utilizado 
Rev. Interd. em Cult. e Soc. (RICS), São Luís, v. 7, n. 2, p. 31- 41, jul./dez. 2021

ISSN eletrônico: $2447-6498$

bem seus últimos momentos para dar a conhecer todo o horror. (SUE apud CHAMAYOU, 2008, p. 342).

Mas se para os partidários da persistência da consciência e da sensibilidade após a decapitação o rubor de Charlotte Corday foi signo inconfundível não só de uma dor física, mas de uma humilhação moral, por outro lado, essa opinião não é unânime: dois dias após a publicação da carta de Sömmerring aparece também no Le Moniteur uma resposta do dr. Georges Wedekind, antigo colega de Sömmerring na Universidade de Mainz e médico do hospital militar de Strasbourg. Ele agrupa os argumentos de seus opositores da seguinte maneira: a sede da alma, da consciência, do senso comum (sensorium commune) está na cabeça (cérebro), cuja organização não é destruída pela guilhotina, de tal modo que a consciência persiste até que a sensibilidade e a irritabilidade desapareçam por completo das partes nervosas; as convulsões das cabeças decepadas são evidência material de que ainda há irritabilidade e sensibilidade nas partes separadas do corpo; finalmente, as convulsões na parte decepada podem ser novamente provocadas quando se irrita a parte da medula exposta, provando que um estímulo externo pode afetar o senso comum mesmo depois da decapitação ${ }^{5}$.

E mesmo que Sömmerring localize a sede da alma no cérebro ${ }^{6}$, isso seria suficiente para concluir a persistência da consciência na cabeça decepada, mesmo sabendo que a guilhotina reúne as duas propriedades para a perda desta consciência, a saber: a compressão do cérebro e a hemorragia? Aqui, deve-se traçar uma separação importante: os movimentos remanescentes provam a persistência da irritabilidade, mas não do sentimento. Para Wedekind, basta tomarmos as convulsões das crises de

\footnotetext{
${ }^{5}$ Uma discussão a respeito do senso comum e da sede da alma é feita em Sobre a obra de Sömmerring: Do órgão da alma (1795), de Kant, inicialmente publicado como anexo ao texto de Sömmerring. (KANT, 2007, p. 96). Ver em especial a nota crítica de n. 3, de autoria de Chamayou (2007, p. 245-46), cujos trechos citamos aqui: $\mathrm{O}$ senso comum "se refere à nossa capacidade de fundir em uma só representação as diversas sensações que nos comunicam os diferentes órgãos dos sentidos. $\mathrm{O}$ 'sensorium commune' é a faculdade que unifica sensações heterogêneas. É a ideia que, para além da simples receptividade sensorial [denominada próton aistheterion], há um sentido que reúne todos os sentidos, um senso comum aos cinco sentidos. O sensorium commune é concebido ao mesmo tempo como um órgão do corpo, e a questão é, então, a de saber qual. A definição da Enciclopédia ilustra esse duplo aspecto, anatômico-metafísico, da questão: 'sensorium, a sede do senso comum. É esse lugar ou parte em que supomos que a alma sensível reside mais imediatamente'. Kant denuncia a confusão dos diferentes registros [...]. A partir de uma análise crítica do conceito de sensorium commune, o que está em jogo é separar a pesquisa anatômica do questionamento metafísica que a anima."

${ }^{6}$ No final do século XVIII, a concepção de força vital começa a substituir a de alma. Ernst Platner, por exemplo, refere-se a uma força vital fundada sobre o fluido nervoso. Sömmering alinha-se a essas teorias, que envolvem outros autores como Albrecht von Haller, Abraham Kaau Boerhaave, Joaquim Dietrich Brandis e Johann Christian Reil, todos localizacionistas, com a especificidade de identificar o senso comum não em um órgão no cérebro, mas no líquido cérebro-espinhal.
} 
Rev. Interd. em Cult. e Soc. (RICS), São Luís, v. 7, n. 2, p. 31- 41, jul./dez. 2021 ISSN eletrônico: $2447-6498$

apoplexia e epilepsia para percebermos que ela é signo de perda da consciência. É possível concluir então que a irritabilidade deve ser definida como uma propriedade independente da sensibilidade e da consciência, e que toda a história que envolve a cabeça de Charlotte Corday é tão crível quanto as histórias de fantasmas que assombram castelos abandonados.

Outra resposta importante dada a Sömmerring e a Sue foi publicada em 15 de novembro de 1795, assinada pelo dr. Lepelletier, "médico, Place de grève, n ${ }^{\circ} 3$ ". Ele argumenta que a guilhotina acaba de uma só vez com as 3 condições necessárias para a vida, que são: a circulação, a respiração e a vibração que resulta da percepção sentimental, que, por sua vez, deriva da unidade do sistema nervoso. Uma personagem curiosa que toma parte nessa discussão é o médico René-Georges Gastellier, declarado inimigo do povo e condenado à guilhotina (e que acabou, na verdade, morrendo apenas em 1821). Ele redige o opúsculo $O$ que pensar, finalmente, do suplício da guilhotina? em que denuncia a confusão entre sensibilidade moral, dor com a irritabilidade das fibras e a sensibilidade puramente mecânica, e argumenta que a violência do golpe (a peça pesava cerca de $40 \mathrm{~kg}$ ) aniquilava a atividade cerebral, ou ao menos a atividade consciente. $\mathrm{O}$ sentimento e o pensamento requerem, para Gastellier, uma integridade da organização completa, que é rompida pela decapitação. Com o golpe da lâmina, "a essência da vida, consequentemente, a essência do sentimento e do pensamento, são atacados". E acrescenta que embora concorde com Wedekind e Lepelletier nas críticas a Sömmerring e Sue, discorda que a guilhotina seja um tipo humano de suplício: "Oh! Quando chegará o tempo em que a sociedade não mais acreditará ter o direito de retirar dos homens uma vida que têm por natureza?" (GASTELLIER apud CHAMAYOU, 2008, p. 35).

É finalmente o célebre fisiólogo francês Cabanis quem irá se posicionar de maneira mais consistente sobre a querela da guilhotina. O texto em questão é Nota endereçada aos autores do Magasin encyclopédique sobre a opinião dos srs. Oelsner e Sömmerring e do cidadão Sue no que concerne ao suplício da guilhotina, pelo cidadão Cabanis (1795). Nesse artigo, o autor se posiciona fisiologicamente sobre os efeitos da decapitação e se opõe filosófica e politicamente à pena de morte. Quanto ao posicionamento fisiológico, desqualifica em primeiro lugar o argumento de Sue (de que a sensibilidade poderia existir em um órgão, independentemente de toda comunicação 
Rev. Interd. em Cult. e Soc. (RICS), São Luís, v. 7, n. 2, p. 31- 41, jul./dez. 2021 ISSN eletrônico: $2447-6498$

com um centro comum - como se uma perna amputada sofresse mesmo sem sua conexão com a cabeça; de que a sensibilidade estaria disseminada e seria exercida em toda parte). A esse respeito, ele escreve:

Vê-se, eu repito, que o cidadão Sue reenvia a irritabilidade à sensibilidade,
como o fizeram muitos homens de gênio. Mas esta ideia, que não nos cabe
aqui examinar e reduzir aos termos precisos, não coloca qualquer dúvida
sobre a questão. Quando uma perna é amputada e cauterizada, não se trata de
saber se há dor nesta perna; quando se irrita a pata de uma rã separada do
corpo, não se trata de saber se há dor nesta pata; mas se o homem a quem
pertencia a perna e se a rã a quem pertencia a pata têm o sentimento ou a
consciência da dor. Ora, é certo que não o têm. Nenhum doente sente as
irritações a que são submetidas seu braço cortado; nenhum animal submetido
vivo à curiosa observação da anatomia dá signos de sensibilidade quando se
dilacera as partes que não estão mais em unidade com ele. (CABANIS, 1795,
p. 164-65).

Feita a separação entre irritação e sensibilidade, para o autor resta esclarecer que a partir do momento em que a comunicação com os centros nervosos cessa, o indivíduo não é mais advertido da sensação no membro separado. Ele rejeita assim a ideia de uma dor existente em uma parte do corpo despregada de um centro para o qual ela deixa de ter significado. Cabanis diferencia em seguida a sensibilidade local das partes vivas e a sensibilidade geral ou a consciência da vida do eu. Ao contrário de Sue, o que interessa na questão levantada não é a persistência de uma sensibilidade difusa nas partes, mas de um ponto que reúne e dá unidade às sensações, que as sintetiza em um centro subjetivo, uma consciência unitária (um eu). O fisiólogo francês afasta a questão colocada por Sue e destaca outra como muito mais importante: a da persistência do sujeito da sensação.

O passo seguinte é rebater o argumento de Sömmerring (da persistência de um sensorium commune ativo e consciente após a decapitação). Muitos fatos, segundo Cabanis, contradizem essa hipótese. Um golpe violento na nuca leva à perda imediata de consciência; além disso, uma grande hemorragia priva rapidamente o cérebro do sangue necessário para o exercício das funções que lhe são próprias. A guilhotina reúne os mecanismos necessários para extinguir imediatamente a vida, e com ela a sensibilidade, a consciência, o eu. Um indivíduo decapitado não sofre, seja no restante do corpo, seja na cabeça decapitada, seja em pensamentos ou julgamentos morais. Sua conclusão é, então, incisiva: a cabeça de Charlotte Corday não ruborizou. 
Rev. Interd. em Cult. e Soc. (RICS), São Luís, v. 7, n. 2, p. 31- 41, jul./dez. 2021 ISSN eletrônico: $2447-6498$

O fato, contudo, de Cabanis rebater os argumentos de Sömmerring e Sue que defendiam a supressão da decapitação - não o fará aderir aos defensores da guilhotina. Ao contrário, ele a condena veementemente. O que o fisiólogo não pode admitir é que o posicionamento político se apoie sobre quimeras. E tanto a moral quanto a ciência devem rechaçar os erros.

Não pretendemos aqui esgotar o percurso - um tanto longo - que levará à formação da noção de reflexo. Para isso fazemos referência ao excelente livro de Canguilhem, A formação do conceito de reflexo nos séculos XVII e XVIII. Para concluir, gostaríamos apenas de destacar um ponto de grande importância para os estudos da consciência e do anímico - ponto que, cremos, terá seus desdobramentos em nosso tempo. Para algumas correntes de pensamento, como a que vemos claramente exposta no capítulo VII de $A$ interpretação dos sonhos, a consciência e o anímico não estão reduzidos à materialidade imediata do corpo, a um ponto específico do cérebro, mas a um ponto virtual, alcançado apenas no nível da representação. Referimo-nos, assim, a um apagamento da remissão do pensamento, da alma, da consciência a um substrato anatomofisiológico. Tal como na pena aplicada aos condenados, algo aqui deixa também de recair diretamente sobre o físico. Aos poucos, o assento vai se deslocando de um órgão localizável no cérebro - uma glândula pineal, por exemplo - para algo mais difuso. Sömmerring terá grande papel nesse debate, pois identifica o sensorium com um fluido: o líquido cérebro-espinhal teria a capacidade de ligar as sensações heterogêneas e garantir a síntese da apercepção. Cabanis irá mais longe: para ele, o eu e a consciência não são entidades distintas, existentes em uma parte do corpo, mas um fenômeno de conjunto, resultado da relação orgânica entre as diferentes partes do corpo vivo. A unidade da consciência corresponderá ao ponto imaterial da unidade do organismo vivo. Segundo Chamayou (2008), Sömmerring e Cabanis representam os dois termos de uma clivagem entre uma concepção tradicional de medicina, fundada em uma leitura analógica do corpo e de seus signos - que buscava a correspondência entre um ponto corporal específico e um ponto virtual de representação -, e uma concepção moderna, que pensa a noção de organismo segundo um modelo muito diferente, não mais meramente mecânico, mas da relação das partes com uma unidade imaterial. Nesse ponto de virada, não devemos nos esquecer, está a querela acerca da cabeça de Charlotte 
Rev. Interd. em Cult. e Soc. (RICS), São Luís, v. 7, n. 2, p. 31- 41, jul./dez. 2021 ISSN eletrônico: $2447-6498$

Corday. De sua morte damos um passo em direção a uma compreensão mais viva, mais orgânica daquele que diz "eu".

\section{REFERÊNCIAS}

CABANIS. Note adressée aux auteurs du Magasin encyclopédique, sur l'opinion de Messieurs Oelsner, Soemmering e du citoyen Sue, touchant le supplice de la guillotine, par le citoyen Cabanis. Magasin encyclopédique, ou Journal des sciences, des lettres et des arts, vol. 5, 1795, pp. 155-174.

CHAMAYOU, G. La querelle des têtes tranchées: les médecins, la guillotine et l'anatomie de l'anatomie de la conscience au lendemain de la terreur. Revue d'histoire des sciences, v. 2, tomo 61, p. 333-365, 2008. Disponível em:

https://www.cairn.info/revue-d-histoire-des-sciences-2008-2-page-333.htm. Acesso em: 01 nov. 2021.

DIDEROT, D. Enciclopédia ou Dicionário razoado das ciências, das artes e dos ofícios. V. 3: Ciências da natureza. Organização e tradução de Pedro Paulo Pimenta e Maria das Graças de Souza. São Paulo: Editora da Unesp, 2015.

FOUCAULT, M. Surveiller et punir. Naissance de la prison. Paris: Gallimard, 1975.

FREUD, S. Die Traumdeutung (1900). In: FREUD, S. Studienausgabe: vol. II. Frankfurt am Main: Fischer, 1972.

KANT, I. Sur l'ouvrage de Sömmerring: De l'organe de l'âme (1795). In: KANT, I. Écrits sur le corps et l'esprit. Tradução e apresentação de Grégoire Chamayou. Paris: Flammarion, 2007.

LE LEXIS. Le dictionnaire érudit de la langue française. Paris: Larousse, 2009.

SANSON, H. Sept générations d'exécuteurs (1688-1847): Mémoires des Sanson. Tomo 4. Paris: Dupray de la Mahérie, 1863. Disponível em:

https://gallica.bnf.fr/ark:/12148/bpt6k367797.texteImage. Acesso em: 01 nov. 2021. 